\title{
Analysis of Consumer's WTP for Cowpea Varieties in Osun State, Nigeria: the Hedonic Pricing Approach
}

\author{
Rabirou Kassali*, Abayomi Yusuf Oyewale, Olufemi Adedotun Yesufu
}

Department of Agricultural Economics, Obafemi Awolowo University, Ile-Ife, Osun State, Nigeria

\section{A R T I C L E I N F O}

\section{Research Article}

Received 01 February 2018

Accepted 20 July 2018

Keywords:

Cowpea varieties

Attributes

Willingness to pay

Hedonic pricing model

Nigeria

*Corresponding Author:

E-mail: kasskassali@yahoo.com \begin{abstract}
A B S T R A C T
Analysis of consumer preferences for cowpea varieties in Osun State was carried out with a view to identifying attributes that determine price variation among cowpea varieties and the effect on consumer's willingness to pay for those varieties. A multistage sampling technique was used to randomly select 240 respondents for the study, comprising 180 cowpea consumers and 60 retailers. Primary data were collected on cowpea varieties, their attributes and the consumer's willingness to pay for cowpea varieties using well structured questionnaire. Data collected were analysed using both descriptive and inferential statistics. The results showed that out of thirteen varieties found in the area, only nine varieties of cowpea were common in the market. The quality of each variety differs which explained variation in their price. In terms of preference the Oloyin variety is preferred most by $78 \%$ of consumers. Weevil resistance had the highest rank among the cowpea attributes. Oloyin had the highest WTP followed by Milk and Drum with $\$ 303, \$ 237$ and $¥ 213$ per kg, respectively. Hedonic pricing methods provide a statistical estimate of premiums and discounts for cowpea attributes. Results indicated that weevil resistance was the most important attribute to consumer. Cowpeas with weevil damage tolerance, brown colour, large grain size and short cooking time commanded price premium for almost all the varieties. The consumer discounted prices for insect damage, small size, white colour, smooth skin and grain colour mixed together. The study concludes on the need for breeders and research institutes to incorporate these cowpea attributes that attracted price premium into their cowpea breeding programmes.
\end{abstract}

DOI: https://doi.org/10.24925/turjaf.v6i9.1120-1128.1832

\section{Introduction}

Cowpea (Vigna unguiculata) is an ancient crop known to man and which was domesticated near Southern Africa, before it was widely spread to East, West Africa and Asia. Today it is grown mostly in semi-arid tropical zones across Africa, Asia, Europe and the Americas (International Institute of Tropical Agriculture [IITA], 2015). Farmers in Africa produced almost $95 \%$ of the global cowpea output on a surface area of more than 11 million hectares followed by Asia (3.2\%), the America $(1.3 \%)$ and Europe $(0.5 \%)$ (FAOSTAT, 2015).

Nigeria is the world's largest producer and consumer of cowpea, accounting for $61 \%$ of production in Africa and 58\% worldwide (IITA, 2015). Between 2000 and 2013 the country produced an average of 2.7 million metric tons of cowpea. In 2011, Nigeria's contribution to global cowpea production dropped to $37.8 \%$, and in 2012 production reached a record high of over five million metric tons (FAOSTAT, 2015). The crop is grown mostly in the semi-arid Central and North West, but also in
North-Central and North-Eastern Nigeria, where it constitutes the most important grain legume crop (Enoch, 2015). Despite its leading position, the country still suffers demand deficit averaging 469,000 tons per annum. It is estimated that Nigeria's average annual imports of 260,000 tons per annum from Niger accounts for about $73 \%$ of Niger's surplus production. Nigeria also imports from Cameroon, Chad and Benin (Langyintuo et al., 2003).

The demand for cowpea in Nigeria is driven by its large population of over 177 million people, with an average growth rate of 2.47 per annum (International Centre for Tropical Agriculture [CIAT], 2014). Since the 1980 s, the increased demand for cowpea has reportedly led to the cultivation of cowpea as a sole crop in many parts of the country (Wakili, 2013). Cowpea is a nutritious component in livestock feed. Its forage contributes significantly to animal feed mainly during the dry season when the demand for feed reaches its peak. 
Cowpeas vary according to the size of the grain, colour, skin texture, eye colour, and insect damage tolerance. The colour of the cowpeas (often referred to as skin colour or testa colour) varies and can be white, black, brown or red. Cowpea skin can be a uniform colour or speckled. The skin or outer coating of the cowpeas can be rough or smooth. The colour of the eye of the cowpeas can be black, grey or brown (Murdock et al., 2003). All these attributes are peculiar to different varieties which stimulate consumer preferences as well as Willingness to Pay (WTP) of the consumers. Dominant varieties of cowpea grown in Nigeria include: IT97K-499-35, IT89KD-288, IT90K-277-2, IT89KD-391, and IT98K205-8 (ICRISAT, 2011). When these varieties reach markets, they become difficult to identify by their code varietal names. They have been categorized in line with physical features and their price premium (Afolami, 2002). Goods are valued by consumers because of their utility-deriving characteristics (Rosen, 1974).

Characteristics of cowpea which influence the quality can be separated into two groups, evident and cryptic characteristics. Evident traits like colour or shape are visible to consumers whereas cryptic traits are not visible and can only be judged after consumption (Buergelt et al., 2009). Examples of cryptic traits are composite ingredients such as sucrose content (sweetness), cooking ability and culinary qualities like swelling capacity. Both types of characteristics, evident and cryptic, are related to each other. In consequence, consumers evaluate evident characteristics, by inferring to certain cryptic characteristics (Jiménez-Portugal, 2004). The effect of these characteristics can be identified through hedonic price function.

A hedonic price model assesses the relationship between the price of a commodity and its economically relevant characteristics. The price is thus expressed as a function of identified attributes and a random error term. The model can be used to predict prices of new goods, adjusting for quality changes in goods or assess consumer's and producer's valuations of given commodities (Rosen, 1974).

A lot of research has gone into the development of improved cowpeas varieties in Nigeria, but the nature of consumer's preferences for cowpeas is yet to be ascertained to guide any future line of actions for breeders, and more importantly the marketers. This study therefore analyses consumer's willingness to pay (WTP) for cowpea varieties as an expression of his preferences for cowpea attributes. The specific objectives are to: (i) identify cowpea varieties and their attributes; (ii) assess consumer's preference and willingness to pay for each variety; and (iii) determine how cowpea attributes influence consumer's willingness to pay for each of the cowpea varieties in the study area.

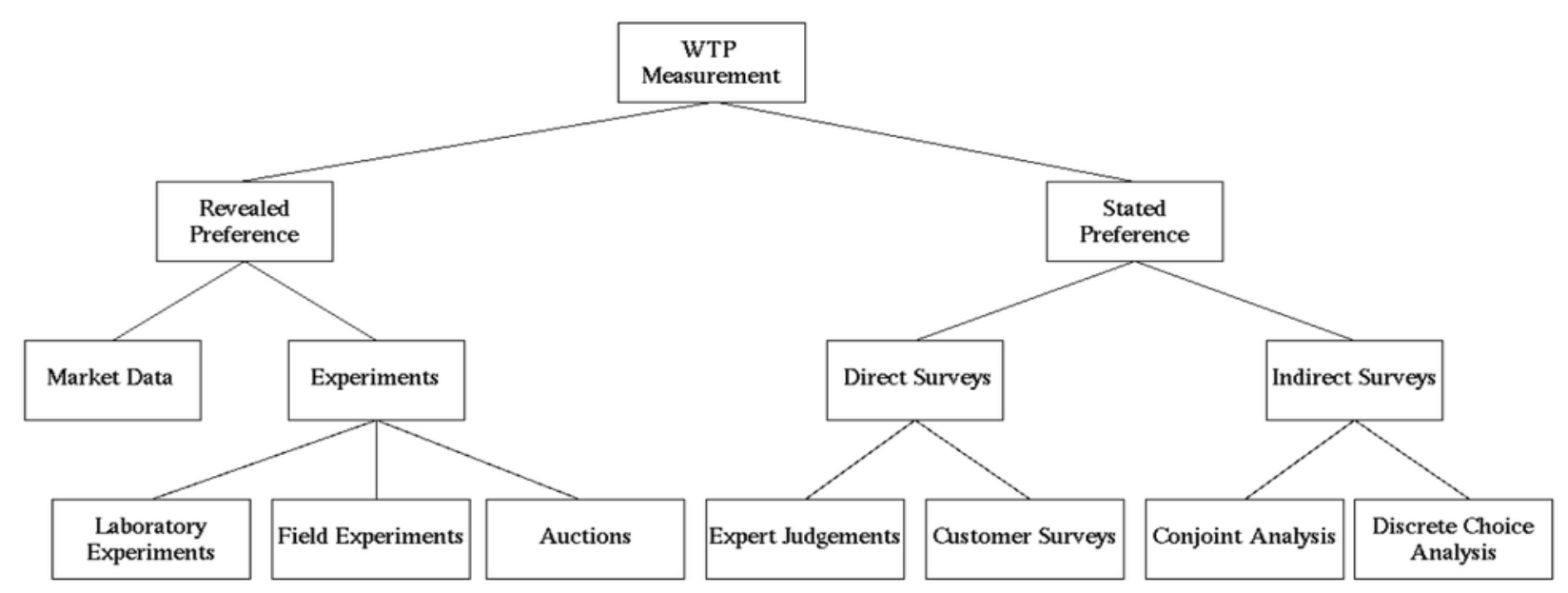

Figure 1 Classification of approaches to assess the willingness-to-pay (Source: Breidert et al., 2006)

\section{Material and Method}

Theoretical Framework

Pearce (1986) defined preference as a statement that a given commodity, event or project is rated higher to one or more other goods. A goods or commodity being an embodiment or mix of attributes that determines its utility to end-user. Consumer preferences are defined as how consumer subjectively rate various bundles of goods based on the utility attached to each. The bundles of goods are therefore ranked according to the levels of utility provided to the consumer. Several approaches are adopted to determine consumer's preferences for a particular item. Preferences are also expressed by willingness to pay (WTP). Pearce (1986) defines willingness to pay as valuation placed on a good or service, while Dossani and Ranganathan (2003) defined it as the maximum price that can be charged without reducing the individual's welfare and utilization of a product. WTP can be captured either through revealed preferences or through stated preferences approaches. Revealed preferences are obtained from price responses while stated preferences are determined from surveys studies. Fig. 1 shows a summary of approaches for assessing WTP. 
Stated preferences in direct surveys are documented by directly asking consumers about their willingness-topay for a certain product whereas indirect surveys use ranking or sorting of products or product characteristics. Conjoint analysis and discrete choice analysis are two examples for indirect surveys. Direct surveys can be further divided into expert judgements and customer surveys reflecting their suitability to deliver accurate WTP estimates. However, this study used customer survey approach. The questions used in the survey can be either open ended or closed ended. In an open-ended question, the respondent is asked to state the monetary amount that he or she is willing to pay for the service that is being valued. With a closed ended CV question (also referred to as "dichotomous choice" or "referendum" question), the respondent is asked whether he or she is willing to pay a specified amount for the good being valued.

\section{The Study Area}

The study was carried out in Osun State. It is located in the south-west geopolitical zone Nigeria. The State is bounded by Ogun State to the South, Kwara State to the North, Oyo State to the West and Ondo State to the East. The State has two distinct climatic seasons. These are the rainy season which is between the months of March and October and the dry season between the months of November and early March. It is one of the land-locked States of the Federal Republic of Nigeria. The State runs an agrarian economy with majority of the populace taking to farming. The State is a typical rain forest with mean annual rainfall varying between $880 \mathrm{~mm}$ and $2600 \mathrm{~mm}$ and temperature ranging between 25 and $27.5^{\circ} \mathrm{C}$. The State covers an area of $14.875 \mathrm{Km}^{2}$ and is made up of 30 Local Government Areas. Osun State is largely urban and has an estimated population of about 3.423.535 people (National Bureau of Statistics [NBS], 2006). It has six major cities. These include Ede, Ife, Ilesha, Ikirun, Iwo and Oshogbo. Ikirun is the gateway through which cowpea is moved to the study area from the Northern part of Nigeria (Kalu and Ajetunmobi, 2013).

\section{Sampling Procedure and Sample Size}

Osun State as the study area was selected because it is one of the consuming states of cowpea in the country. A multi-stage sampling technique was used to obtain primary data from the respondents. In the first stage, six Local Government Areas (LGAs) were purposively selected due to their high population density. At the second stage, three towns were randomly selected in each of the LGAs. At the third stage, a random selection of 10 households in each town was done, making asample of 180 households. In addition, 10 cowpea retailers were randomly selected from each LGA making a total of 240 respondents (180 consuming households +60 cowpea retailers) for the study.

\section{Data Collection}

The primary data from households and retailers were collected through interviews using structured and semi structured questionnaires. Information collected included; household characteristics, tastes and preferences, sensory evaluation, prices of different varieties that consumers were willing to pay and actual market prices of various varieties of cowpeas in the market.

Consumers were shown samples of each variety found in the markets and were asked to rate each variety according to its evident traits like size, shape and colour which were visible to consumers and cryptic traits like meal making suitability, cooking ability and swelling capacity which were not visible and can only be judged after consumption. The rating was between very bad to excellent (1=very bad, 2=bad, 3=fair, 4=good and $5=$ excellent) or (Not Important $=0$, Important $=1$ ). Respondents were asked open ended questions of how much they were willing to pay per kilogram of each variety. They were given chance to re-arrange their rankings and willingness to pay values. After evaluating the above attributes, consumers were asked about their awareness and knowledge about the different varieties. Retailers were contacted to elicit information on available cowpea varieties and actual market price of each variety. Following Unnevehr (1986), all information was collected within one week in this case in the month of August, in order to minimize price variance due to factors other than quality and each variety was coded to eliminate name bias and before presenting it to respondents. Similarly, information on attributes provided by the respondents were cross checked against taxonomic information on the cowpea varieties that are well documented, so as to verify whether consumer's perception of varietal attributes is consistent with existing scientific records (Unnevehr, 1986).

\section{Descriptive Statistics}

Descriptive statistics was used to the data on identified cowpea varieties and attributes, consumer's preference, WTP by the consumers and actual market price of each variety.

\section{Empirical Model}

Most researchers have estimated the hedonic function using regression technique. Consumer's good price is regressed against its characteristics to derive a coefficient representing the implicit price of the characteristics. This approach has been used by Ibrahim et al., (2013); Kalu and Ajetunmobi (2013); Mundua (2011); LowenbergDeBoer, (2001); Veeman and Adomowiez (2000); Faye (1999); Brorsen et al. (1984); Triplett, (1986); Dalton (2004).

For each of the Variety, the following hedonic equation was specified:

$$
\mathrm{Pi}=\alpha+\sum \beta i X i+v
$$

Where,

$P i \quad=$ Willingness to pay for a Kilogram of cowpea grains for variety $i$ in Naira.

$X i \quad=$ Consumption attribute

$\beta i=$ Regression estimates or implicit price of the attributes

$v \quad=$ Stochastic error term 
Cowpea attributes $\left(\mathrm{X}_{\mathrm{i}}\right)$ in the model are specified as follows:

$\mathrm{X}_{1}=$ Seed coat colour $(1=$ Very bad; $2=$ Bad; 3 = Fair; 4= Good; 5= Excellent)

$\mathrm{X}_{2}=$ Seed shape $(1=$ Very bad; $2=\mathrm{Bad} ; 3=$ Fair; $4=$ Good; 5= Excellent)

$\mathrm{X}_{3}=$ Meal suitability $(1=$ Very bad; $2=$ Bad; 3 = Fair; $4=$ Good; 5= Excellent)

$\mathrm{X}_{4}=$ Grain size $(1=$ Very bad; $2=\mathrm{Bad} ; 3=$ Fair; $4=$ Good; 5= Excellent)

$\mathrm{X}_{5}=$ Grain eye colour $(1=$ Very bad; $2=$ Bad; 3 = Fair; 4= Good; 5= Excellent)

X6 = Seed swollen capacity $(1=$ Very bad; $2=\mathrm{Bad} ; 3=$ Fair; 4= Good; 5= Excellent)

$\mathrm{X}_{7}=$ Sucrose content (sweetness) (1=Very bad; $2=$ Bad; 3 = Fair; 4= Good; 5= Excellent)

$\mathrm{X}_{8}=$ Seed aroma on cooking $(0=$ Not important; $1=$ Important)

$\mathrm{X}_{9}=$ Grain damage tolerance $(1=$ Very bad; $2=$ Bad; $3=$ Fair; 4= Good; 5= Excellent)

$\mathrm{X}_{10}=$ Grain colour mixes $(0=$ Not important; $1=$ Important)

$\mathrm{X}_{11}=$ Grain size mixes $(0=$ Not important; $1=$ Important $)$

$\mathrm{X}_{12}=$ Texta texture $(0=$ Not important; $1=$ Important $)$

$\mathrm{X}_{13}=$ Time taken for grain to cook (mins)

For the empirical estimation, out of the functional forms tested, the linear form provided the best fit, with value of Adjusted $\mathrm{R}^{2}$ within range and in accordance with Jiménez-Portugal (2004), Mundua (2011). All estimations were subjected to diagnostic tests, such as F-test, covariance matrix and collinearity test.

\section{Results and Discussion}

Cowpea Varieties in The Study Area and Their Attributes

Table 1 shows the cowpea varieties and their attributes as found in the study area. About thirteen varieties were found but only nine varieties were common in the market. The varieties are Gombe, Drum, Olo, Oloka, Sokoto, Milk, Wuwo, Oloyin, Jibia, Otili, Ife brown, Ife bimpe and Feregede. The last four varieties were not common in the market. Each of the varieties had distinct attributes ranging from seed coat colour, seed shape, size, eye colour, cooking time, swelling capacity, weevil tolerance, testa texture and sucrose content (sweetness).

\section{Variety Preferred Most by The Respondents}

Table 2 shows the varieties most preferred by the consumers. Majority (77.8\%) preferred Oloyin while about $5.6 \%$ only preferred Sokoto, against $3.9 \%$ eachfor Drum, Jibia, Milk and Wuwo, respectively and $1 \%$ for Gombe. The choices of the consumers might be based on the attributes peculiar to each variety, actual end product and utility to be derived.

\section{The Scores and Rank of Cowpea Attributes}

Table 3 shows the scores and rank of the attributes of cowpea by the respondents. The respondents using their knowledge of the crop scored all the attributes according to their importance when purchasing cowpea in the market. According to the consumers, the most economically relevant attribute of cowpea is weevil tolerance (that is the ability to resist insect damage or having zero insect damage at the point of purchase). Among the thirteen attributes considered, weevil tolerance had the highest score of 2139 and subsequently ranked first among the thirteen attributes scored. It is important to note that while one advantage of cowpeas grain is that grains can be stored for use throughout the year, a major disadvantage is that cowpea grains are prone to insect damage. It is generally understood that consumers prefer cowpeas with less insect damage (Murdock et al, 2003). The discount for damage also probably depends on the type of food being prepared. Bruchid holes would be visible in foods that use whole cowpea, but unnoticeable in products that use milled cowpea (Fulgence et al., 2007). Consumers are more sensitive to bruchid damage than hypothesized. It was thought that consumers would tolerate a certain level of damage, but the data indicates that cowpea prices are discounted from the first appearance of damage (Fulgence et al., 2007). The second ranked attribute was sweetness of the cowpea which is due to the presence of sucrose and the third was cooking time. Cooking time has a significant impact on price while sucrose contents tend to provide a premium. This is an indication that consumers prefer cowpea with high sucrose contents and less cooking time (Faye et al., 2006).

The grain size mixes and grain colour mixes were ranked $13^{\text {th }}$ and $12^{\text {th }}$ respectively. These two attributes were scored low because most of the varieties that ranked high neither had the grain size nor the grain colour mixed together.

Table1 The identified cowpea varieties and their attributes*

\begin{tabular}{l|l}
\hline \multicolumn{1}{c|}{ Local Name } & \multicolumn{1}{c}{ Characteristics } \\
\hline Gombe & White seeded and medium sized, brown eye colour and traditional variety \\
Drum & Brown testa colour, large sized, white eye colour and modern variety \\
Olo & Brown testa and small seeded, white eye colour and traditional variety \\
Oloka & Whitish brown seeded, medium sized, black eye colour and traditional variety \\
Sokoto & White seeded and medium sized, black eye colour and traditional variety \\
Milk & Milk colour and medium sized, greyish eye colour and modern variety \\
Wuwo & White seeded, large sized, black speckled eye colour and modern variety. \\
Oloyin & Brown seed, medium sized, brown speckled eye colour and modern variety. \\
Jibia & White seeded and medium sized, brown eye colour and traditional variety \\
\hline *Source: Field survey, 2015
\end{tabular}


Table 2 Cowpea varieties and level of preference by the consumers*

\begin{tabular}{l|ccc}
\hline \multicolumn{1}{c|}{ Varieties } & Frequency & Percent & Cumulative Percent \\
\hline Drum & 7 & 3.9 & 4.4 \\
Gombe & 2 & 1.0 & 5.0 \\
Jibia & 7 & 3.9 & 8.9 \\
Milk & 7 & 3.9 & 12.8 \\
Oloyin & 140 & 77.8 & 90.6 \\
Sokoto & 10 & 5.6 & 96.1 \\
Wuwo & 7 & 3.9 & 100.0 \\
Total & 180 & 100.0 & \\
\hline
\end{tabular}

*Source: Field survey, 2015

Table 3 The scores and Rank of cowpea attributes as perceived by consumers*

\begin{tabular}{l|rcrc}
\hline \multicolumn{1}{c|}{ Attributes } & Score & Average & Stand Deviation & Ranking \\
\hline Weevil tolerance & 2139.00 & 11.88 & 2.10 & $1^{\text {st }}$ \\
Sweetness & 1915.00 & 10.64 & 2.08 & $2^{\text {nd }}$ \\
Time to cook & 1827.00 & 10.15 & 1.97 & $3^{\text {rd }}$ \\
Swelling & 1625.00 & 9.03 & 2.32 & $4^{\text {th }}$ \\
Coat colour & 1544.00 & 8.58 & 2.01 & $5^{\text {th }}$ \\
Foreign materials & 1531.00 & 8.51 & 2.86 & $6^{\text {th }}$ \\
Grain size & 1480.00 & 8.22 & 1.55 & $7^{\text {th }}$ \\
Meal making & 1277.00 & 7.09 & 1.83 & $8^{\text {th }}$ \\
Shape & 959.00 & 5.33 & 1.23 & $9^{\text {th }}$ \\
Aroma & 708.00 & 3.93 & 1.62 & $10^{\text {th }}$ \\
Eye colour & 695.00 & 3.90 & 2.29 & 1.52 \\
Colour mixes & 394.00 & 2.19 & 1.62 & $11^{\text {th }}$ \\
Size mixes & 281.00 & 1.57 & & $12^{\text {th }}$ \\
\hline
\end{tabular}

*Source: Field survey, 2015

Table 4 Cowpea varieties and the consumer's willingness to pay

\begin{tabular}{l|cr}
\hline Varieties & WTP(Naira/kg) & STD \\
\hline Gombe & 160.5517 & 5.1096 \\
Drum & 213.7407 & 21.0647 \\
Olo & 148.2592 & 25.7077 \\
Oloka & 150.1111 & 6.0497 \\
Sokoto & 166.0741 & 1.4329 \\
Milk & 237.7037 & 26.4979 \\
Wuwo & 206.9259 & 25.6054 \\
Oloyin & 303.4074 & 41.2217 \\
Jibia & 167.6296 & 0.1762 \\
\hline
\end{tabular}

*Source: Field survey, 2015

Cowpea Varieties and The Willingness to Pay by Consumers

Table 4 shows the willingness to pay per kilogram by consumers for the nine common varieties of cowpeas identified in the study area. It was observed that Oloyin had the highest WTP followed by Milk and Drum. The highest WTP of Oloyin may be due its sweetness and the ease of cooking which were the $2^{\text {nd }}$ and $3^{\text {rd }}$ most important attributes as ranked by consumers. Drum also shares one similarity with Oloyin and Milk which is its red coat colour that was ranked as the $5^{\text {th }}$ most important attributes. Olo and Oloka had the least WTP among the nine varieties. This might be due to low level of awareness of these varieties as none of the consumers mentioned these two as their most preferred varieties. Besides, these varieties are small sized cowpeas and consumers tend not to like small grain attribute. Sokoto, Gombe and Jibia had almost the same WTP. This can be deduced from the fact that the three varieties have white seed coat and medium size.
Analysis of Market Potential of Cowpea Varieties

Table 5 shows the market potential of cowpea varieties by comparing willingness to pay and market prices of the identified varieties. The result showed that consumers were ready to pay premium of 29.7901 , $\aleph 2.0265, \aleph 37.4738, \aleph 36.2116, \aleph 58.2963$ and $¥ 0.7502$ for Drum, Sokoto, Milk, Wuwo, Oloyin and Jibia, respectively and a discount of - $\$ 7.2261$,- 36.3562 , and $\$ 8.5556$ for Gombe, Olo and Oloka, respectively. These results mean amount of premium consumers were willing to pay was $\$ 58$ for Oloyin, $\$ 37$ for Milk, $\$ 36$ for Wuwo and $\$ 30$ for Drum. Oloyin and Milk share the same similarity in terms of coat colour and ease of cooking while Wuwo and Drum share similarity in terms of large grain size. All these attributes are the most preferred by consumers which might be responsible for the premium consumers are willing to place on each. Consumers also discounted a huge amount of -N36 for Olo. This might be because of the low level of awareness, unattractive physical appearance and small size of this variety. 
Table 5 Identification of market potential of cowpea varieties ${ }^{*}$

\begin{tabular}{l|ccrrr}
\hline \multicolumn{1}{c}{ Variety } & WTP(NAIRA/KG) & Market Price $(\mathrm{N} / \mathrm{KG})$ & \multicolumn{1}{c}{ DIFF. } & \multicolumn{1}{c}{ STD } & t-value \\
\hline Gombe & 160.5517 & 167.7778 & -7.2261 & 5.1096 & 0.298 \\
Drum & 213.7407 & 183.9506 & 29.7901 & 21.0647 & 10.161 \\
Olo & 148.2592 & 184.6154 & -36.3562 & 25.7077 & -8.871 \\
Oloka & 150.1111 & 158.6667 & -8.5556 & 6.0497 & -7.608 \\
Sokoto & 166.0741 & 164.0476 & 2.0265 & 1.4329 & 1.801 \\
Milk & 237.7037 & 200.2299 & 37.4738 & 26.4979 & 5.408 \\
Wuwo & 206.9259 & 170.7143 & 36.2116 & 25.6054 & 20.248 \\
Oloyin & 303.4074 & 245.1111 & 58.2963 & 41.2217 & 10.319 \\
Jibia & 167.6296 & 168.8788 & 0.7502 & 0.1762 & 4.225 \\
\hline * Soure: Field
\end{tabular}

*Source: Field survey, 2015

Table 6 Results from estimated hedonic model for attributes of cowpea varieties ${ }^{1}$

\begin{tabular}{|c|c|c|c|c|c|c|c|c|c|c|}
\hline Variable & $\begin{array}{l}\text { Gombe } \\
\text { Coeff }\end{array}$ & t. value & $\begin{array}{l}\text { Drum } \\
\text { Coeff }\end{array}$ & t. value & Olo Coeff & t. value & $\begin{array}{l}\text { Oloka } \\
\text { Coeff }\end{array}$ & t. value & $\begin{array}{c}\text { Sokoto } \\
\text { Coeff }\end{array}$ & t. value \\
\hline Coat & 6.933 & $1.908 *$ & 2.156 & (5) & -1.16 & -0.397 & 0.155 & & -2.009 & 06 \\
\hline Seed shape & -5.322 & $-1.65^{*}$ & -0.857 & 96 & 96 & 0.375 & 0.010 & $0 .($ & -1.202 & -0.442 \\
\hline Meal suitable & 11.208 & $3.542 * * *$ & 2.714 & 0.538 & -8.59 & $-2.16 * *$ & -2.228 & & 3.660 & 1.530 \\
\hline Grain size & -0.300 & -0.087 & 9.791 & $2.361 * *$ & -7.43 & $-2.06 * *$ & -1.149 & -0.282 & 6.523 & $2.455 * *$ \\
\hline Eye colour & -6.400 & $-2.29 * *$ & -0.500 & -0.115 & & & -13.74 & -3.7 & -1.095 & \\
\hline Swelling & -6.616 & $-2.37 * *$ & -6.65 & -1.51 & 54 & $-2.41 * *$ & 1.854 & 0.5 & -1.623 & -0.629 \\
\hline Sweetness & -3.644 & -1.22 & -10.16 & $-2.24 * *$ & 11.61 & $2.978 * * *$ & 1.102 & 0.242 & 1.250 & 0.478 \\
\hline Aroma & -8.308 & -1 & -6.71 & -0.8 & -17.36 & -1. & -9.394 & -1.14 & -6.165 & -1.18 \\
\hline W. tolerance & 2.780 & & 5.300 & 0.702 & 26.16 & $3.233 * * *$ & 0.897 & 0.100 & 5.278 & 0.791 \\
\hline Colou & -.576 & -0.075 & -13.31 & -.828 & -8.459 & & 1.369 & 0.1 & -10.924 & $-1.91 *$ \\
\hline Size mixes & -3.801 & -0.518 & -19.7 & -1.35 & -19.0 & -1.37 & -10.81 & -0.874 & 14.586 & $2.302 * *$ \\
\hline & 2.420 & & -0.737 & -.038 & 40.31 & $2.112 *$ & -8.242 & -0.580 & 3.955 & 0.441 \\
\hline Cook time & -0.023 & -0.171 & -0.360 & $-1.73^{*}$ & 0.228 & $1.633^{*}$ & 0.402 & $2.534 * *$ & -0.152 & -1.29 \\
\hline F-test & $2.403 * *$ & & $2.44 * *$ & & $3.24 * * *$ & & $2.45 * *$ & & $2.41 * *$ & \\
\hline $\mathrm{R}^{2}$ & 0.214 & & 0.217 & & 0.267 & & 0.220 & & 0.217 & \\
\hline
\end{tabular}

\begin{tabular}{l|cccccccc}
\hline \multicolumn{1}{c}{ Variable } & Milk Coeff & t. value & Wuwo Coeff & t. value & Oloyin Coeff & t. value & Jibia Coeff & t. value \\
\hline Coat colour & -7.27 & -1.10 & 1.764 & 1.151 & 12.479 & 1.357 & 5.597 & -.528 \\
Seed shape & 1.632 & 0.250 & 2.814 & $2.050^{* *}$ & -15.027 & $-1.817 *$ & 0.354 & 0.499 \\
Meal suitable & 16.04 & $3.066^{* * *}$ & 1.362 & 0.879 & -7.429 & -0.692 & 1.278 & $3.110^{* * *}$ \\
Grain size & 6.484 & 0.982 & .802 & 0.476 & -2.141 & -0.257 & 1.085 & -0.330 \\
Eye colour & -4.39 & $-2.44 * *$ & -1.692 & -1.188 & 3.215 & 0.344 & 1.089 & 0.602 \\
Swelling & -1.69 & $-0.293^{* * *}$ & -0.448 & -0.294 & -7.850 & -1.102 & -0.673 & $1.814 *$ \\
Sweetness & -1.71 & -0.275 & -0.809 & -0.549 & -6.353 & -0.572 & 5.597 & 0.326 \\
Aroma & -8.46 & $-1.63^{* *}$ & 2.943 & 1.036 & -5.094 & -0.493 & 0.354 & $-2.26^{* *}$ \\
W. tolerance & 1.254 & 0.122 & 13.406 & $4.481 * * *$ & 42.448 & $2.372 * *$ & 1.278 & 1.056 \\
Colour mix & -53.3 & $-2.79 * * *$ & 2.942 & 0.644 & -33.945 & -1.192 & 1.085 & -1.52 \\
Size mixes & -12.7 & -0.807 & -6.075 & -0.899 & 6.579 & 0.201 & 1.089 & $2.764 * * *$ \\
Testa texture & 11.88 & 0.613 & 2.311 & 0.335 & 2.849 & 0.108 & -0.673 & 0.564 \\
Cook time & 0.339 & 1.212 & -0.072 & -0.881 & -0.703 & -1.290 & 5.597 & -1.24 \\
F-test & $2.19 * *$ & & $3.08 * * *$ & & $3.14 * * *$ & & $2.24 * *$ & 0.203 \\
R & 0.203 & & 0.261 & & 0.263 & & & \\
\hline
\end{tabular}

${ }^{1}$ Source: Data analysis, 2015, NB:* Significant at 10\%; ** Significant at 5\%; *** Significant at $1 \%$

Effects of Cowpea Attributes on WTP For Cowpea Varieties

The results of the estimation are presented in Table 6. All estimations per cowpea variety showed a significant result as attested by a significant F-test value. Results indicate that the impact of seed coat colour on WTP was significant for Gombe and Drum. The coat colours of both varieties show positive relationship with WTP. Consumers were willing to offer a premium of 6.93 and * 2.16 for Gombe and Drum respectively. Therefore, consumers were indifferent about the coat colour since they offer premium for both although they offer more premium for white coat colour (Gombe). This is in agreement with the study of Faye et al. (2006) on the influence of cowpea characteristics on cowpea price in Senegal, it was revealed that consumers were willing to pay a premium for red skin colour but discounted price for black skin compared to white skin colour which was the preferred variety. Langyintuo et al. (2004) also reported that in northern Ghana, consumers paid a premium for white cowpeas. 
Grain shape was significant for Gombe, Wuwo and Oloyin. It was observed from the result that the seed shape has a negative relationship on WTP for Gombe and Oloyin but positive for Wuwo Consumers discounted price of $\$ 5.32$ and 15.03 for Gombe and Oloyin respectively but paid a premium of 2.81 for Wuwo. This shows that consumers did not put seed shape into consideration when making choice for cowpea even though they offer premium for Wuwo, this might be due to it big size which shows its fine kidney shape. This has also been shown by Mundua (2011) that consumers did not think of seed shape being an important property in determining meal making suitability of cowpea. Meal making suitability is the ability to prepare a tasty meal from cowpea. The attribute was significant for Gombe, Olo, Milk and Jibia. This was positive for Gombe, Milk and Jibia but negative for Olo. Consumers offer a premium of $\$ 11.21$, 16.04 and $\$ 1.28$ for Gombe, Milk and Jibia respectively but discount price for Olo. All the cowpeas were suitable for meal making the reason for the case of Olo was that, the variety is not common in the open market and consumers were not familiar with it. This is consistent with the assertion of Mundua (2011) that all the cowpea samples used had positive meal making suitability relationship with consumer WTP; this implies that consumers were willing to pay a premium for all the varieties, as regard meal making suitability.

Grain size is one of the crucial attributes for consumers when making purchase of cowpea varieties. However, this attribute was statistically significant for three varieties: Drum, Olo, and Sokoto. The grain size for Drum and Sokoto showed a positive relationship with WTP while it was negative for Olo. For a unit increase in grain size, consumers were willing to pay a premium of 9.79 and $\$ 6.52$ for Drum and Sokoto respectively while they discounted price of $\$ 7.43$ for Olo. The reason being that, consumers preferred large grain size to small grain size. Drum which had a high premium of $\$ 9.79$ is a large size cowpea and Sokoto with 6.53 is a medium size cowpea while Olo which consumers are less willing to pay ( 7.43) is a small sized cowpea. This shows that consumers have preference for large grain size cowpea. This might be probably because it yields large amount of flour when milled. This is consistent with Faye et al. (2006) in Senegal, where consumers were willing to pay a premium for additional increase in grain size. This is not different from Langyintuo et al. (2004) who reported same in Cameroon and Northern Ghana, where consumers generally preferred large undamaged cowpea grain. Ibrahim et al. (2013) also found that consumers were willing to pay 0.96 for each additional gram of grain weight.

Consumers seemed not to be concerned with the eye colour of cowpea varieties as hedonic pricing model suggested negative relationship of the attribute with WTP for all varieties that were statistically significant. This can thus be deduced that eye colour was not valued by consumers in their choice of cowpea varieties. This is consistent with Fulgence et al. (2007) who stated that the coefficient for grain eye colour was negative and statistically significant in the markets in Southern Ghana and Mali. Faye et al. (2006) also affirmed that price was discounted for black eye cowpea in Senegal.
Swelling capacity was negatively significant for Gombe, Olo, Milk and Jibia. Consumers discounted price for the attribute in all the four varieties that showed some level of significance contrary to a priori expectation. Although Milk has a poor swelling ability which the model rightly suggested, the other varieties Gombe and Olo have a fairly good swelling capacity. Consumers seem to be indifferent about the swelling ability of Jibia though the coefficient was negative but not statistically different from zero because it has excellent swelling ability. The reason for the negative assertion of Gombe and Olo with WTP might be due to the fact that these two varieties were not common in open market except the customers specially demanded for it unlike Sokoto and Jibia which consumers believe have high swelling ability and can be processed into various forms of cowpea dishes.

Sweetness which depends on the sucrose content of cowpea was significant for Drum and Olo. Hedonic model suggests negative and positive relationship with WTP for Drum and Olo, respectively. Consumers were willing to pay a premium of 11.61 for a unit increase in sucrose content for Olo but discounted price of 10.16 on Drum. It seems that consumers were indifferent about the sweetness of Drum presumably because they value its attractive red coat colour and large grain size but not its sweetness. This is partly in line with Faye et al. (2006) where sucrose content provides premium for cowpea.

Aroma is the scent which emanated from cowpea while on cooking or after it has been prepared into dishes. Aroma was statistically significant for Olo, Milk and Jibia. Although consumers seem not to consider aroma as an important attribute of cowpea because it was argued by some of the consumers that aroma was not an important attribute for cowpea varieties, rather it is the condiments added to it that matter. Therefore, the negative relationship of the attribute was as expected.

The major disadvantage of cowpea is that it is highly susceptible to insect damage. Weevil damage tolerance is the ability of cowpea to resist insect damage or have no sign of insect damage or bruchid holes at the point of purchase or even when stored at home. Weevil damage tolerance was statistically significant and positive for Olo, Wuwo and Oloyin. Consumers offered a premium of $\$ 26.16$, 13.41 and $\$ 42.45$ for an increase in weevil tolerance for Olo, Wuwo and Oloyin respectively. This is in line with Fulgence et al. (2007) where consumers discounted the price of cowpea by $0.5 \%$ for every additional bruchid hole. Langyintuo et al. (2003) also found out that price was discounted about $1.2 \%$ per bruchid hole. This shows that consumers detested cowpea with insect infestation. Therefore, they were ready to offer a premium for any variety that had high level of insect resistance.

Colour mix was significant for Sokoto and Milk which had white and milk colours, respectively. The colour mix had negative relationship with WTP for the two varieties that were statistically significant. Consumers discounted price of $\$ 10.92$ and $\$ 53.3$ for any trace of another colour appearing in Sokoto and Milk, respectively. Consumers discounted as high as $\$ 53.3$ for any trace of another colour in Milk because it is a standalone variety that has a very attractive coat colour, hence mixing it with any other 
colour would affect its market value. This indicates that colour is an important attribute of cowpea for consumers; therefore, any attempt to mix the unique colour of any variety will reduce consumer's preference.

Grain size mix was statistically significant for Sokoto and Jibia as consumers offered a premium of $\$ 14.59$ and \#1.09 for Sokoto and Jibia respectively for any trace of different sizes mixed together. This shows that consumers prefer sizes mixed together for Sokoto and Jibia.

The cooking time of cowpea depends on its skin texture (Faye et al., 2006). Cowpea can either have rough or smooth skin texture. A rough skin texture cowpea cooks faster than smooth skin texture. All the varieties of cowpea in the market had rough skin texture that was why skin texture was not significant for all the varieties except for Olo where consumers offered a premium of $\$ 40.31$ for its rough skin texture while cooking time was only significant for Wuwo and Oloka. The implicit prices of these two varieties were almost zero which signified that consumers paid no attention to the cooking time because all the varieties had rough skin textures which cook easily although they cook faster than one another. This agreed with Ibrahim et al. (2013) who reported that, consumers were willing to pay a premium of $\$ 40.64$ for rough testa texture, and Faye et al. (2006) who observed that some consumers appeared to be indifferent on cowpea skin texture, while others discounted prices for smooth skin cowpeas.

\section{Conclusion and Recommendations}

Nine varieties of cowpeas were common in the in the study area. These were Gombe, Drum, Olo, Oloka, Sokoto, Milk, Wuwo, Oloyin, and Jibia. Oloyin was the most preferred variety followed by Milk and Drum. Six varieties: Drum, Sokoto, Milk, Wuwo, Oloyin and Jibia showed great market potential with their WTP higher than their actual market prices. Most consumers preferred cowpeas with brown coat colour, large grain size, weevil damage tolerance, grain size mix and rough testa texture, while they seem to be indifferent on seed shape, eye colour, swelling capacity, cooking time and aroma. Consumers were less willing to Pay for colour mix cowpea with insect damage, small grain size and smooth skin texture. Based on the findings of the study, the following recommendations were made to enhance the utility and profit to consumers and farmers, respectively:

- The most preferred attributes which attract premium price such as large grain size, brown coat colour, weevil damage resistance, grain size mixes and rough texta texture should be the focus for Research Institute on the cowpea improvement in Southwest Nigeria in general and other stakeholders. This will enable the breeders to come up with cowpea variety that encompasses all the attributes preferred by consumers.

- Researchers should develop simple appropriate storage technologies for adoption by consumers and retailers.

\section{References}

Afolami CA. 2002. An Empirical Analysis of Variety Price Premium Attributes, Spatial and

Temporal Pricing Patterns for Cowpeas in Ogun state, Nigeria. African Crop Science Journal, 10(3): 263-270.

Breidert C, Hauser M, Schmidt-Thieme L. 2006. A review of methods for measuring willingness-to-pay, Innovative Marketing, 32p.

Brorsen W, Grant RG, Rister EM. 1984. A Hedonic Price Model for Rough Rice: Bid/Acceptance Markets, American Journal of Agricultural Economics, 66: 156 - 163.

Buergelt D, von Oppen M, Yadavendra, JP. 2009. Quality parameters in relation to consumer's preference in ricebean. International Conference on Grain Legumes: Quality Improvement, Value Addition and Trade held at IIPR, Kanpur, India, February 14-16, 2009.CIAT 2014. Tropical Legumes II Project, Research Report No 1, 116p.

Dalton TJ. 2004. A household hedonic model of rice traits: economic values from farmers in West Africa. Agricultural Economics Elsevier B.V Economics and Management, 26: 271-292.

Dossani R, Ranganathan V. 2003. Farmers' Willingness to Pay for Power in India: Conceptual Issues, Survey Results, and Implications for Pricing.

Enoch W. 2015. Cowpeas production in Nigeria. A silent food resolution. Outlook on Agriculture, 45(2): 125-130.

Faye M, Jooste A, Lowenberg-DeBoer J, Fulton J. 1999. The Influence of Cowpea Characteristics on Cowpea Prices in Senegal, Agrekon, 43(4): 418-429.

Faye MD. 2005. Investigations of key aspects for the successful marketing of cowpeas in Senegal. Published PhD Thesis. Department of Agricultural Economics, University of the Free State, Bloemfontein, South Africa.

Faye M, Jooste M, Lowenberg-Deboer J, Fulton J. 2006. Impact of sucrose contents and cooking time on cowpea prices in Senegal. South African Journal of Economic and Management Sciences, 9(2): 207-212.

FAOSTAT. 2015. Food and Agriculture Organization Statistics, What is Conservation Agriculture? Available from: http://www.fao.org/ag/ca/1a.html. Accessed, 02 May, 2015.

Fulgence JM, Fulton J, Musa S, Marfo SKK, Chergna MJA, Lowenberg-DeBoer J. 2007. Consumer preferences for quality characteristics along the cowpea value chain in Nigeria, Ghana and Mali. Department of Agricultural Economics, Purdue University, Working Paper \#06-17.

Ibrahim FD, Nmadu, JN, Baba KM, Gana AS, Danbaba N, Ibrahim PA. 2013. Demand Analysis for Consumer Preference of Cowpea Attributes in Niger State Journal of Agriculture and Veterinary Science, 5(5): 67-72.

ICRISAT 2011. Bulletin of Tropical Legumes. Available from: http: $\quad$ www.icrisat.org/tropicallegumes11/pdfs/BTL122011223. Accessed: 13 May, 2012.

IITA 2015. Cowpea. [Online]. Available from: http://www.iita.org/cowpea. Accessed, 25 April, 2015.

Jiménez-Portugal LA. 2004. Relevant quality attributes of edible dry beans. Journal of the Market Research Society, 59(2): 160-180.

Kalu UI, Ajetunmobi JO. 2013. Consumers' Preference for Cowpea in Nigeria. International Journal of Agricultural Management and Development, pp.19-26

Langyintuo A, Lowenberg-DeBoer J, Faye M, Lambert D, Ibro G, Moussa B, Kergna A, Kushwaha S, Musa S, Ntoukam G. 2003. Cowpea Supply and Demand in West and Central Africa. Field Crops Research, 82: 215-231. 
Langyintuo A, Ntoukam G, Murdock L, Lowenberg_DeBoer J, Miller DJ. 2004. Consumer Preference for Cowpea in Cameroon and Ghana. Agricultural Economics, 30: 203213.

Lowenberg-DeBoer J. 2001. Trip Report - Bean/Cowpea Collaborative Research Support Progam, Purdue University.

Mundua J. 2011. Estimation of Consumer Preferences For Cowpea Varieties In Kumi And Soroti Districts. Unpublished M.Sc. Thesis. Makarere University Uganda.

Murdock LL, Seck RE, Ntoukam G, Kitch L, Shade RE. 2003. "Preservation of Cowpea Grain in Sub-Saharan Africa Bean-Cowpea CRSP contributions. Field Crops Research, 82: 69-178.

NBS. 2006. National Bureau of Statistics, Annual Abstract of Statistics. (FRN), 300p.

Pearce DW. 1986. Macmillan Dictionary of Modern Economics. Third Ed. Macmillan Reference Books. Macmillan Press Limited. USA. 462 pp.
Rosen S. 1974. Hedonic prices and implicit markets: product differentiation in pure competition. Journal of Practical Economics, 82: 34-55.

Triplett J. 1986. Handbook on Hedonic Indexes and Quality Adjustments in Price Indexes: Special Application to Information Technology Products OECD Science, Technology and Industry.

Unnevehr LJ. 1986. Consumer demand for rice grain quality and returns to research for quality improvement in south-east Asia. Am. J. Agric. Econ. 68: 634-641.

Veeman M, Adomowiez V. 2000. Consumers' perceptions of environmental risks and the demand for food safety. Project Report 00-01. Edmonton: University of Alberta, Department of Rural Economy.

Wakili AM. 2013. Economic analysis of cowpea production in Nigeria. Russian Journal of Agricultural Economics. and Socio-Economic Science, 1(13): $60-63$. 